\title{
Implementação do sistema de gerenciamento de processos: estudo na área de aeródromos
}

\author{
Implementation of the process management system: \\ a study in the aerodrome area
}

Francisco Henrique Figueiredo Araujo ${ }^{1}$

Leonardo Vils ${ }^{2}$

\begin{abstract}
Resumo
O presente relato tem como objetivo apresentar o projeto como ferramenta para realizar as adaptações normativas necessárias à implementação de tecnologia de informação e comunicação (TIC), no setor público, e demonstrar o aumento da eficiência na prestação de serviço aos cidadãos, após a melhoria dos processos e utilização de TIC, na área de aeródromos. Este relato possui uma abordagem exploratória-descritiva, utilizando a metodologia de estudo de caso. Os dados foram obtidos mediante análise documental e levantamento dos registros existentes no sistema implementado. A principal contribuição é a relevância de projetos para implementação de inovação na administração pública e consequente aumento na eficiência, percebida como benefício pelo cidadão.
\end{abstract}

Palavras-chave: Projeto; Normas; TIC; Processos; Eficiência; Benefícios.

\section{Abstract}

This report aims to present the project as a tool to make the necessary regulatory adaptations for the implementation of information and communication technology (ICT) in the public sector. And yet,

\footnotetext{
Engenheiro Eletricista, Centro Universitário da Fundação Educacional Inaciana Pe. Sabóia de Medeiros - FEI. São Bernando do Campo, SP - Brasil. Aluno do Mestrado Profissional em Administração - Gestão de Projetos da Universidade Nove de Julho - UNINOVE. São Paulo, SP - Brasil. ORCID: https://orcid.org/0000-0001-8787-308X | fhfaraujo@uni9.edu.br

Doutorado em Admnistração: Univerdidade Nove de julho - Uninove - SP - Brasil. ORCID: https://orcid.org/0000-0003-3059-1967 | leonardo.vils@uni9.pro.br
}

Como citar:

Araujo, F. H. F., \& Vils, L. (2020). Implementação do sistema de gerenciamento de processos: estudo na área de aeródromos. Revista Inovação, Projetos e Tecnologias, 8(1), 41-50. https://doi.org/10.5585/iptec.v8i1.17399 
demonstrate the increase in efficiency in the provision of services to citizens, after the improvement of processes and use of ICT, in the aerodrome's area. This report has an exploratory-descriptive approach, using the case study methodology. The data were obtained through document analysis and survey of existing records in the implemented system. The main contribution is the relevance of the project for the implementation of innovation in public administration and the consequent increase in efficiency, perceived as a benefit by the citizen.

Keywords: Project; Standards; ICT; Processes; Efficiency; Benefits.

\section{Introdução}

A segurança da navegação aérea é de interesse coletivo, e, assim, o Estado tem o poder-dever de impor restrições ao direito de propriedade com vistas à conformação deste aos ditames da segurança no voo (Neves, 2012). A Constituição Federal outorga à União a competência privativa para legislar sobre direito aeronáutico (Artigo 22, I).

Especificamente sobre a tutela da segurança de voo no entorno de aeródromos, o comando constitucional é densificado pelo Código Brasileiro de Aeronáutica - CBA (Lei n 7.565, de 19 de dezembro de 1986), que dispõe sobre a proteção da zona aeroportuária (Lima, 2012).

Dessarte, o Comando da Aeronáutica (COMAER), por meio do Departamento de Controle do Espaço Aéreo (DECEA), atendendo sua prerrogativa legal, desde o CBA, vem editando as normas na área de aeródromos. A área de aeródromos, do inglês Aerodrome Ground Aids (AGA), é responsável, dentre outras atribuições, pela análise dos processos de implantação de objeto projetado no espaço (OPEA), como por exemplo: edificações, pontes, antenas, torre, linhas de transmissão etc.

Esses regulamentos prescrevem que, a depender da localização de um empreendimento, faz-se necessária a análise do COMAER para que a implantação do OPEA possa ser autorizada, ou não. Até 2015, para se obter essa deliberação o interessado deveria protocolar o pedido em um dos sete Comandos Aéreos Regionais (COMAR). Esta solicitação era expressa em um requerimento padrão e deveria vir acompanhado de, no mínimo, anotação de responsabilidade técnica (ART), carta da região e desenho do perfil do aproveitamento, tudo em 2 vias com firma reconhecida em cartório.

Naquela época, os COMAR dependiam de pareceres externos, principalmente, quanto aos aspectos relacionados a regularidade e segurança das operações aéreas. Esses pareceres eram emitidos por outros órgãos, geralmente, situados em localidades diferentes. Como todo o trâmite processual era realizado de forma física, não eram raros os casos em que a deliberação demorava mais de um ano para ser emitida. Além deste fato, não existia uma forma efetiva de acompanhamento do processo tanto pelos interessados quanto pelos gestores.

Com o propósito de atender aos anseios da sociedade por um serviço mais eficiente, sob o ponto de vista de facilidade de acesso, transparência e diminuição do prazo de resposta o DECEA estabeleceu um projeto com escopo de realizar a revisão normativa necessária para aprimorar o fluxo processual e desenvolver um sistema capaz de gerenciar os processos e realizar a interface com o cidadão e demais organizações militares.

Diante deste contexto, esta pesquisa foi norteada pela seguinte questão: o projeto é uma ferramenta adequada para realizar revisões normativas, melhorar processos e implementar Tecnologia de Informação e Comunicação (TIC), no setor público? E ainda, essas mudanças podem influenciar positivamente a eficiência do serviço prestado, do ponto de vista dos cidadãos?

Para isso, será apresentado, inicialmente, um referencial teórico sobre os benefícios da inovação tecnológica e sua contribuição para a eficiência nas organizações, em especial, naquelas que desempenham, por força de legislação, tarefas intrinsecamente burocráticas e de caráter regulatório. Ato contínuo, será exposto um histórico das ações resultantes do projeto, descrevendo o desenvolvimento das normas desde a edição do CBA até os dias atuais. 
No próximo passo, apresentar-se-á o contexto e a motivação para criação do Sistema de Gerenciamento de Processos da Área de Aeródromos (SYSAGA) e, por fim, pretende-se demonstrar ganho de eficiência sob o ponto de vista da melhoria nos processos referente a análise de OPEA.

\section{Referencial teórico}

No setor público, a gestão eficiente depende de gestores competentes e de pessoas engajadas que elaborem projetos concretos e que os implementem com responsabilidade. Para este fim são elaboradas as políticas públicas, que têm o propósito de atender os anseios da sociedade, através de adoção de ações concretas, que beneficiem a todos de maneira ampla (Vieira \& Montenegro, 2016).

Praticamente todas as implementações de políticas públicas são "projetizadas", ou seja, possíveis de serem abordadas sob a perspectiva de projeto e, portanto, podem ser conduzidas de acordo com os preceitos do gerenciamento de projetos. Este ramo da Administração é bastante valorizado por sua capacidade de realizar transformações positivas nas organizações além de apresentar potencial relevância para que os objetivos traçados sejam alcançados (Pinheiro \& Rocha, 2012).

Para Grander, Dal Vesco e Ribeiro (2019) é preciso reconhecer e defender que os projetos devem estar alinhados com os objetivos estratégicos das organizações e que precisam entregar benefícios desejados e definidos pelas partes interessadas. No contexto deste estudo, o benefício é compreendido como o aumento da eficiência na entrega de serviços públicos e melhoria na capacidade de resposta do Estado aos anseios da sociedade.

No mesmo sentido, Musawir, Serra, Zwikael e Ali (2017) defendem que as organizações precisam reconhecer que o objetivo final dos projetos é obter benefícios. Além disso, os gestores devem buscar essa visão orientada a benefícios e incorporar as responsabilidades pela realização de benefícios no sistema de governança de projetos, permitindo assim o desenvolvimento e a implementação de um processo abrangente de gerenciamento de benefícios.

Convém destacar que, na geração de inovação, além dos fatores relacionados aos funcionários, os aspectos relativos ao ambiente de trabalho no qual o projeto está inserido também são importantes. Existe uma suposição comum entre os estudiosos de organização que formas temporárias de organização, tal como os projetos, são especialmente adequados para gerar inovação (Spanuth \& Wald, 2017).

As administrações públicas usam cada vez mais as tecnologias da informação e comunicação (TIC) para garantir maior acesso, transparência e eficiência na prestação de serviços aos seus usuários, sejam cidadãos, empresas ou outros órgãos públicos. Esse uso de TIC é qualificado como 'governo eletrônico' na literatura existente (Andersen \& Henriksen, 2006).

De acordo com os achados de Lima, Arenas e Souza (2018), as inovações tecnológicas representam uma ferramenta relevante no aperfeiçoamento dos procedimentos organizacionais, simplificando processos, modificando fluxos, eliminando atividades desnecessárias, automatizando outras. Diante disso, os autores afirmam que a Administração Pública não pode deixar de incorporar os benefícios oportunizados pela TIC em suas atividades, implicando em vantagens tanto para o Estado quando para o servidor público e sociedade em geral.

A incorporação das TIC proporciona maior agilidade nos trâmites administrativos, empregando um menor tempo e dispondo de menos pessoas para realizar a mesma atividade, o que implica em maior eficiência. Deste modo, essa eficiência se traduz em melhor desempenho, com celeridade, qualidade no serviço prestado e o consequente alcance de resultados organizacionais melhores. (Lima et al., 2018)

Além dos aspectos de qualidade, segurança e rapidez dos serviços para o cidadão, 
simplificação dos procedimentos e diminuição da burocracia, o sucesso dos projetos para implantação de governo eletrônico deve ter como base o valor criado pelos benefícios vivenciados e também pelo valor percebido pelos cidadãos que utilizam serviços eletrônicos (Alshibly \& Chiong, 2015). Se, por um lado, a entrega de serviços públicos deve economizar tempo e dinheiro dos cidadãos, por outro lado, inovação em governo só faz sentido quando se entrega valor às pessoas (Comitê Gestor da Internet no Brasil, 2018).

Evidencia-se, portanto, a necessidade de reforma da Administração Pública, passando de um modelo burocrático para as variações do gerencialismo público. Dentro deste novo paradigma, que prega a modernização administrativa, a utilização de gerenciamento de projetos pelo setor público é uma forma de melhorar a capacidade de resposta do Estado aos anseios da sociedade. (Zouain, Souza, \& Parreira, 2012).

Sem deixar de lado os princípios basilares das Forças Armadas, quais sejam a Hierarquia e Disciplina, o DECEA instituiu um projeto para condução desta modernização administrativa na área de aeródromos. O projeto teve como escopo realizar a revisão das normas e permitir o avanço tecnológico necessário para a prestação de serviços por meio de uma plataforma digital, possibilitando a entrega de um benefício à sociedade qual seja maior eficiência na tramitação dos processos da área de aeródromo.

\section{Método da produção técnica}

O primeiro passo da pesquisa foi uma breve revisão da literatura, apresentada na seção anterior. Seguindo o protocolo de Biancolino, Kniess, Maccari, e Rabechini Junior (2012), arquitetou-se um estudo de caráter exploratório-descritivo, que visa incrementar o conhecimento acerca do problema e descrever a solução tecnológica implementada na organização com foco na melhoria dos serviços prestados.

$\mathrm{Na}$ pesquisa utilizou-se a metodologia do estudo de caso, desenvolvida por Yin (2015), com objetivo de apresentar "como" e "porque" o projeto de adaptações normativas possibilitou a implementação de um sistema digital e este, que por sua vez, contribuiu para a entrega de benefícios aos interessados.

A essência do método baseia-se em uma estratégia para pesquisa empírica empregada para a investigação do fenômeno contemporâneo, em seu contexto real, possibilitando a explicação de ligações causais de situações singulares (Yin, 2015).

Embora não tenha-se um roteiro rígido para o estudo de caso, para este relato, o delineamento foi definido da seguinte forma: partindo-se do processo de análise de OPEA como unidade de análise, executou-se a coleta de dados por meio de documentos (leis e portarias) e da base de dados do SYSAGA; na sequência foi realizada a seleção, análise e interpretação dos dados; e, por fim, foi elaborada a conclusão com a apresentação do ganho de eficiência gerado pelo projeto de adaptações normativas e implementação de TIC.

O projeto foi conduzido por profissionais do DECEA reunidos em um Grupo de Trabalho, não havendo a participação direta do pesquisador neste grupo. O acompanhamento e resultados foram observados diretamente, pelo pesquisador, durante o desenvolvimento de suas atividades laborais, como Chefe da Seção de Aeródromos do Serviço Regional de Engenharia do Quarto COMAR e posteriormente como Chefe da Seção de Coordenação e Controle da Subdivisão de Aeródromos do Serviço Regional de Proteção ao Voo de São Paulo (SRPV-SP). 


\section{Situação problema}

O Comando da Aeronáutica é responsável por zelar pela segurança e regularidade das operações aéreas e pela preservação das Zonas de Proteção dos Aeródromos. Por consequência, possui a competência para estabelecer as ações que devem ser executadas pelos agentes públicos no tocante aos processos de análise das construções no entorno dos aeródromos.

Embora, a luz da Portaria $n^{\circ} 1141 /$ GM5, de 8 de dezembro de 1987, fosse previsto um modelo padronizado de requerimento, naquela época, o interessado era obrigado a realizar a entrega do formulário e demais documentos (carta da região, desenho do perfil do aproveitamento, etc.) fisicamente no Comando Aéreo Regional (COMAR) responsável pela área na qual o objetivo estivesse inserido.

Isto significava, por exemplo, que o processo de um OPEA localizado em Belo Horizonte precisava ser protocolado no Rio de Janeiro (COMAR3), em seguida, seria encaminhado para Brasília, para receber um parecer técnico. Após análise técnica, retornaria ao Rio de Janeiro para consolidação do parecer e confecção de resposta ao interessado a qual era expressa em um Ofício enviado pelos correios de volta a Belo Horizonte.

Como todo o trâmite realizava-se de forma física, era comum o interessado ter que aguardar meses para ser informado sobre uma eventual não conformidade no processo. Também, não eram raros, os casos em que um processo demorava mais de um ano para obter uma deliberação. Ressaltase, ainda, que durante este período o único modo de acompanhar a situação de um processo era realizar contato, durante o horário do expediente administrativo, com o COMAR onde o processo havia sido protocolado.

Naquela época, embora os agentes envolvidos e as principais competências estivessem definidos em ato normativo, qual seja a Portaria $n^{\circ}$ 1141/GM5 e sua sucessora Portaria $n^{\circ}$ 256/GC3, de 13 de maio de 2011, os procedimentos eram estabelecidos de acordo com o entendimento local de cada COMAR, mais especificamente por cada Serviço Regional de Engenharia através de Normas Padrão de Ação e o atendimento ao público era realizado, prioritariamente, de modo presencial.

Pelo modo como o processo era estabelecido, percebia-se o descontentamento dos interessados, principalmente, quanto: a demora para receber uma deliberação; a necessidade de apresentar a documentação física no COMAR (por vezes, localizado em outro estado); e a ausência de informação da situação do processo.

Destaca-se ainda, que a ausência de um sistema informatizado para suportar todo o processo, dificultava a tomada de decisão dos gestores no sentido de diminuir esse prazo ou mesmo fazer o acompanhamento dos processos.

\section{Tipo de intervenção e mecanismos adotados}

Em 2011, com objetivo de aprimorar os serviços prestados a sociedade a qual ansiava pela redução dos prazos de resposta, o DECEA deu início a um projeto (Pinheiro \& Rocha, 2012; Vieira \& Montenegro, 2016) - conduzido por um Grupo de Trabalho, composto por membros de diversas Organizações Militares, Órgãos Regionais, Especialidades, Tempo de Serviço, Postos e Graduações Hierárquicas - para revisar a regulamentação e implementar um sistema de gerenciamento dos processos.

Durante a fase de planejamento do projeto a equipe realizou visita técnica aos COMAR com intuito verificar a realidade dos processos em andamento. Embora pudesse se observar o empenho dos profissionais, era notório, do ponto de vista processual, que havia oportunidade para melhoria. Identificou-se, dentre outros óbices: a falta de um sistema informatizado para controlar os processos; 
a tramitação dos processos realizados de forma física e muitos encaminhamentos efetuados manualmente.

Para que o projeto atingisse o objetivo, evidenciou-se a necessidade de eliminação de etapas puramente burocráticas do processo. O tempo de tramitação entre um setor e outro, realizado de forma física, também foi identificado com gargalo. Assim, idealizou-se a tramitação digital de documentos e um novo formato para os processos.

$\mathrm{Na}$ etapa de execução do projeto, os Órgãos Regionais do DECEA - composto pelos Centros Integrados de Defesa Aérea e Controle de Tráfego Aéreo (CINDACTA) e SRPV-SP - começam a desenvolver sistemas locais, no intuito de gerenciar os processos e aprimorar a emissão dos pareceres técnicos.

Ao constatar a perda de eficiência, pela ausência de padronização nos processos e adoção de metodologias distintas entre os regionais, o projeto elaborou as Instruções do Comando da Aeronáutica (ICA) 63-19/2011 e 11-3/2012, a primeira voltada para os critérios de análise técnica e a segunda para padronização do fluxo processual, em nível nacional.

Em consonância com as instruções, foi incorporado ao grupo de trabalho do projeto, na fase de execução, especialistas em controle de tráfego aéreo com conhecimento em desenvolvimento de software. Esses profissionais desenvolveram - a partir do sistema local do SRPVP-SP - o Sistema de Gerenciamento de Processo da Área de Aeródromos com abrangência nacional.

Concomitantemente, foram redesenhados os fluxos processuais os quais, para atender ao princípio da legalidade (intrínseco à administração pública), demandaram novas revisões normativas. Nessa reformulação dos processos foi contemplada a utilização do software para suportar as atividades da área de aeródromos.

Por fim, com base nesse trabalho, o projeto foi concluído com a entrega da Portaria $\mathrm{n}^{\circ}$ 957/GC3, de 9 de julho de 2015, e as reedições dos ICA 11-3 e ICA 63-19, que juntas possibilitaram: a tramitação do processo de modo digital; maior transparência; redução do tempo de resposta; e ganho de eficiência.

\section{Resultados obtidos e análise}

O processo de análise de construções no entorno de aeródromos, até 2015, tramitava completamente por meios físicos. A interface com o interessado era realizada pelos COMAR, com atendimento prioritariamente presencial. Não existia um sistema digital unificado para realizar a tramitação e o acompanhamento dos processos. 


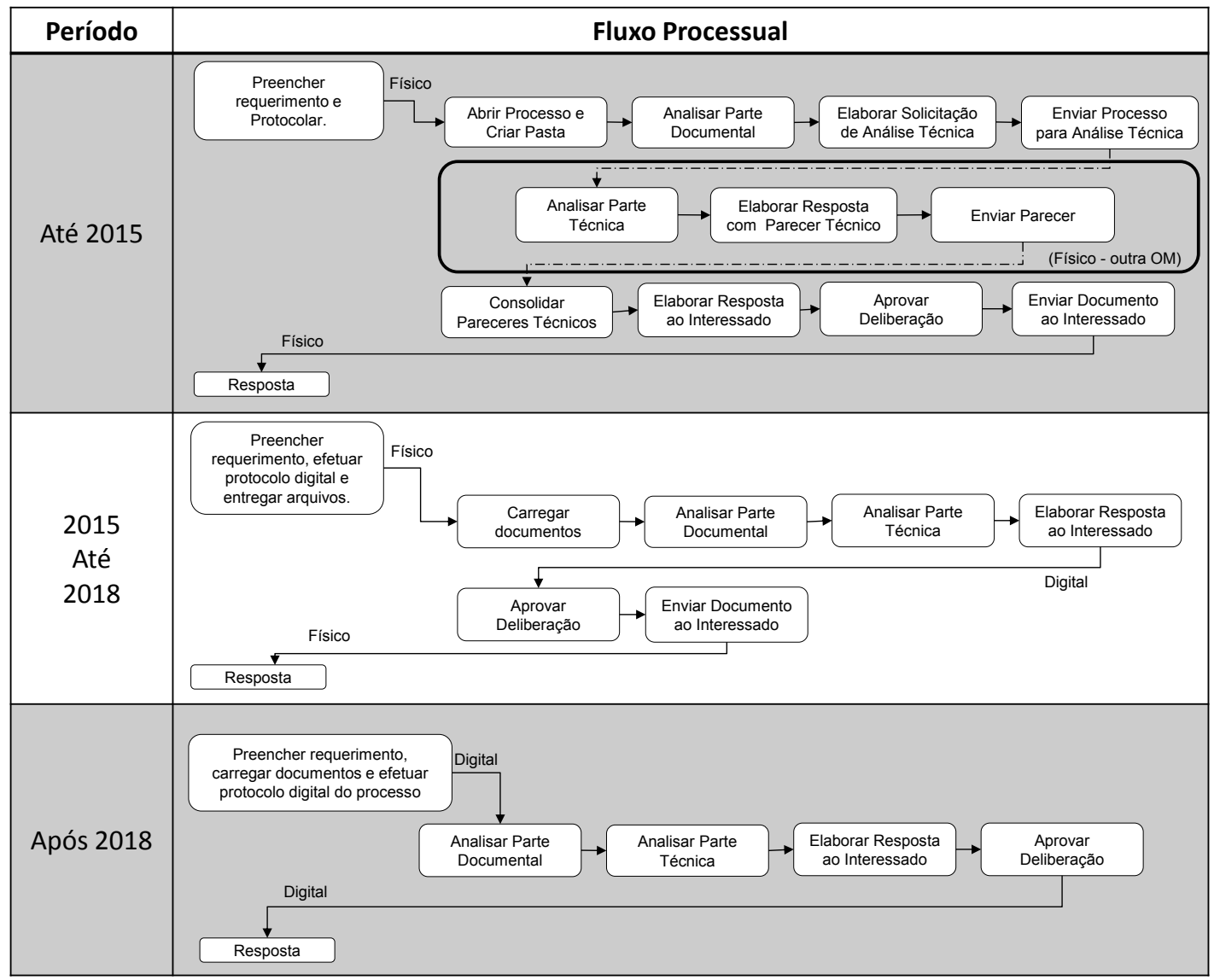

Figura 1 - Evolução do fluxo processual realizado pelo projeto de adequação das normas afeta a área de aeródromos

Fonte: Os autores.

Visando melhorar essa tramitação, o projeto de revisão normativa, editou a Portaria $\mathrm{n}^{\mathrm{o}}$ 957/GC3 e realizou as reedições das ICA 11-3 e 63-19. Por conseguinte, a partir 15 de outubro de 2015, houve a primeira mudança significativa do fluxo processual, conforme apresentado na Figura 1. Os processos passaram a ser protocolados diretamente nos Órgãos Regionais do DECEA eliminando a tramitação física entre COMAER e Órgãos Regionais - e começam a ser suportados pelo sistema em âmbito nacional.

Neste ponto do desenvolvimento do projeto pode-se verificar um avanço, do ponto de vista das competências e do fluxo processual. No entando, a documentação do processo - em grande parte digital - ainda deveria ser entregue pelo interessado diretamente nos Órgãos Regionais e as deliberações mantinham-se por meio de documentos físicos os quais eram expedidos pelos correios.

Diante disso, como pode-se verificar na Figura 2, nos anos de 2015, 2016 e 2017 embora o tempo de resposta tive diminuído praticamente pela metade se comparado a quando os processos entravam pelos COMAR e previsão seguir fisicamente para obtenção dos pareceres, o tempo de resposta ainda estava elevado.

Um aspecto que pode ter contribuído para essa inércia nos primeiros anos da nova regulamentação é o fato de que era necessário lidar, concomitantemente, com um enorme passivo que tramitava no regime antigo, amparado pelo Artigo 126 da Portaria n $\mathrm{n}^{\circ}$ 957/GC3.

Finalmente, a partir de $1^{\circ}$ de outubro de 2018, com a edição da ICA 11-3/2018, o projeto cumpre seu escopo, e os processos passam a tramitar de maneira completamente eletrônica, ou seja, os documentos são carregados diretamente no sistema, pelo interessado, de qualquer lugar onde se tenha acesso à internet. 
Além desse benefício, com o sistema tornou-se possível o acompanhamento do processo em tempo real; a tramitação entre um departamento e outro passou a ser executado de forma eletrônica; e a deliberação passou a ser realizada em um documento nato digital, com assinatura eletrônica e acessado diretamente no sistema, indo ao encontro dos estudos de Andersen e Henriksen (2006) e Spanuth e Wald (2017).

Para demonstrar a eficiência obtida com a utilização de TIC proposta por Lima et al. (2018), traduzida pela redução no tempo médio de resposta nos processos de análise dos OPEA no entorno dos aeródromos, utilizou-se os dados, disponíveis no SYSAGA, relativos aos processos na área do SRPV-SP, a partir de 15 de outubro de 2015, quando entrou em vigor o marco regulatório estabelecido pelo advento da Portaria no 957/GC3, ICA 11-3/2015 e ICA 63-19/2015.

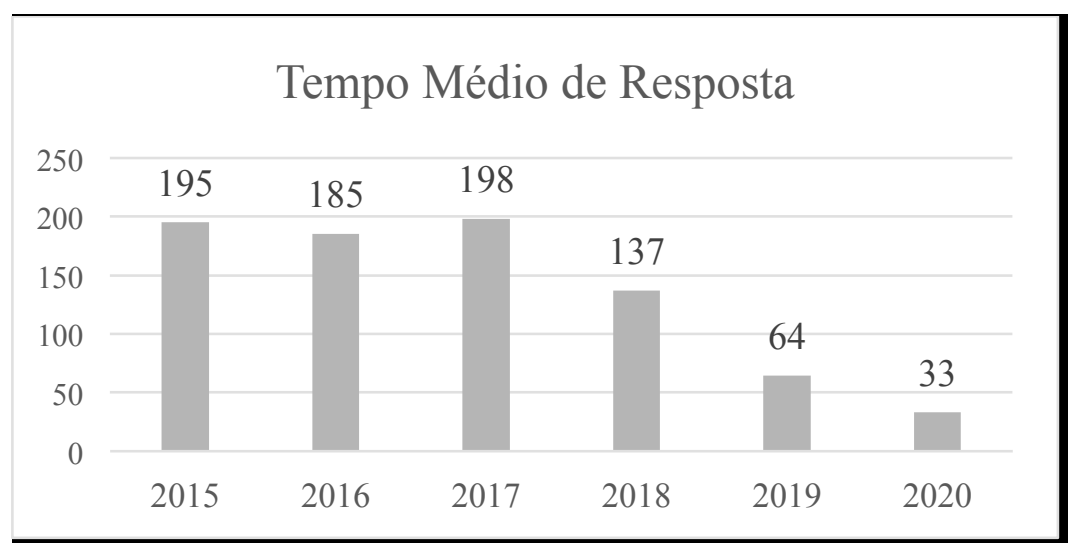

Figura 2 - Tempo médio de resposta, em dias, dos processos de análise de objeto projetado no espaço aéreo na área de abrangência do SRPV-SP a partir de 15 de outubro de 2015

Fonte: Os autores.

Desta feita, como ilustrado pela Figura 2, torna-se claro a diminuição no tempo de resposta aos pedidos dos interessados. Com início da tramitação completamente digital, em 2018, percebe-se o início da redução no tempo de resposta, a qual reduz-se em aproximadamente $50 \%$ no ano seguinte.

Corroborando com os estudos de Lima et al. (2018), além de TIC, verificou-se maior agilidade nos trâmites administrativos com a simplificação dos procedimentos e diminuição da burocracia, Figura 1. Essa inovação representa um fator de sucesso do projeto que teve por base entregar benefícios aos cidadãos (Alshibly \& Chiong, 2015).

Cumpre-se destacar que não foi possível contabilizar, neste relato, os processos anteriores a 2015, devido ao fato de a tramitação naquela época ocorrer de maneira física e sem um sistema capaz de mensurar o tempo médio daqueles processos.

\section{Conclusão}

O objetivo deste relato foi apresentar o projeto desenvolvido para realização das adaptações normativas necessárias ao aprimoramento do fluxo processual e à inserção das Tecnologias da Informação e Comunicação nos processos na área de aeródromos, mais especificamente dos objetos projetados no espaço aéreo no entorno dos aeródromos. A meta do projeto visava atender aos anseios da sociedade por um serviço mais eficiente corroborando com os estudos de Pinheiro e Rocha (2012), Vieira e Montenegro (2016) e Spanuth e Wald (2017).

Analisando os resultados à luz das inovações tecnológicas (Lima et al., 2018) foi possível identificar que o projeto resultou no aperfeiçoamento dos procedimentos, simplificação dos 
processos, maior agilidade nos trâmites administrativos. Esses resultados melhoraram a qualidade do serviço prestado, tornando-o mais efetivo, transparente e acessível.

As constatações obtidas por esse estudo contribuem para a literatura, reforçando os achados de Alshibly e Chiong (2015) e Lima et al. (2018), ao demonstrar que a inovação tecnológica, representada pela implementação das TIC na administração pública, potencializam o sucesso do projeto. Esta inovação proporcionou rapidez aos serviços para o cidadão, simplificação dos procedimentos e diminuição da burocracia, criando valor percebido pelos cidadãos que utilizam este serviço.

Além disso, como contribuição prática, ratifica os achados de Pinheiro e Rocha (2012) e Spanuth e Wald (2017), no sentido de que o projeto é uma ferramenta adequada para implementação de inovação na administração pública e consequente aumento na eficiência. E também, confirma os estudos de Grander et al. (2019) e Musawir et al. (2017), indicando que os projetos devem estar alinhados com os objetivos estratégico das organizações e que precisam entregar benefícios desejados e definidos pelas partes interessadas.

Após relacionar os temas estudados foi então possível responder ao problema da pesquisa deste artigo evidenciando que o projeto é uma ferramenta adequada para realizar revisões normativas, melhorar processos e implementar TIC, no setor público. E ainda, que as inovações melhoram a eficiência do serviço prestado e entregam benefícios a sociedade.

Quanto às limitações deste relato, destaca-se a análise de um caso único com o foco somente no benefício apresentado pela melhoria dos processos e pela redução do tempo de resposta nos processos da área de aeródromos. Sugere-se que pesquisas futuras possam identificar esses benefícios em outras áreas da administração pública ou ainda identificar outros ganhos proporcionados pelas TIC.

Por fim, este relato apresentou um projeto como ferramenta para prover inovação tecnológica, melhorar a eficiência e entregar benefícios, especialmente, em organizações que desempenham, por força de legislação, tarefas intrinsecamente burocráticas e de caráter regulatório.

\section{Referências}

Alshibly, H., \& Chiong, R. (2015). Customer empowerment: Does it influence electronic government success? A citizen-centric perspective. Electronic Commerce Research and Applications, 14(6), 393-404. https://doi.org/10.1016/j.elerap.2015.05.003

Andersen, K. V., \& Henriksen, H. Z. (2006). E-government maturity models: Extension of the Layne and Lee model. Government Information Quarterly, 23(2), 236-248. https://doi.org/10.1016/j.giq.2005.11.008

Biancolino, C. A., Kniess, C. T., Maccari, E. A., \& Rabechini Junior, R. (2012). Protocolo para Elaboração de Relatos de Produção Técnica. Revista de Gestão e Projetos - GeP, 3(2), 294-307.

Comitê Gestor da Internet no Brasil (2018). Pesquisa sobre o uso das tecnologias de informação e comunicação no setor: TIC governo eletrônico 2017. Recuperado de https://www.cetic.br/media/docs/publicacoes/2/TIC_eGOV_2017_livro_eletronico.pdf

Grander, G., Dal Vesco, D. G., \& Ribeiro, I. (2019). O efeito da governança de projetos e da gestão da realização de benefícios na estratégia das organizações: uma análise multigrupo sob o prisma de indicadores de desempenho. Revista de Gestão e Projetos, 10(2). https://doi.org/10.5585/gep.v10i2.13965

Lima, A. M. S., Arenas, M. V. S., \& Souza, V. (2018). Inovação no serviço público federal para aquisição de passagens aéreas: tecnologia, eficiência e legalidade / Innovation in the federal public service for acquisition of air tickets: technology, efficiency and legality. Brazilian Journal of Development, 4(4), $1217-1235$. 
Lima, A. C. (2012). A Tutela da Segurança de Voo em face do Uso do Solo no Entorno de Aeródromos - O Poder de Polícia Aeronáutico à Luz da Portaria n 256/GC5, 2011 - COMAER. Revista Conexão SIPAER, $4(1), 115-128$.

Musawir, A. U., Serra, C. E. M., Zwikael, O., \& Ali, I. (2017). Project governance, benefit management, and project success: Towards a framework for supporting organizational strategy implementation.

International Journal of Project Management, 35(8), 1658-1672. https://doi.org/10.1016/j.ijproman. 2017.07.007

Neves, M. I. (2012). A Indenização decorrente da Servidão em Torno de Aeródromos e Heliportos. Revista Conexão SIPAER, 4(1), 183-190.

Pinheiro, M. T., \& Rocha, M. (2012). Contribuições do escritório de gerenciamento de projetos públicos na gestão para resultados. Revista do Serviço Público, 63(2), 199-215. https://doi.org/10.21874/rsp.v63i2.95

Spanuth, T., \& Wald, A. (2017). How to unleash the innovative work behavior of project staff? The role of affective and performance-based factors. International Journal of Project Management, 35(7), 13021311. https://doi.org/10.1016/j.ijproman.2017.07.002

Vieira, M. D. G., \& Montenegro, C. A. A. (2016). A busca pela eficiência no serviço público, através da lei de acesso à informação e as relações com o aprimoramento da gestão da informação. Saber Humano: Revista Científica da Faculdade Antonio Meneghetti, 6(8), 121-135.

Yin, R. K. (2015). Estudo de caso: Planejamento e métodos (5. ed.). Porto Alegre: Bookman.

Zouain, D. M., Souza, F. S. R. N. de, \& Parreira, T. J. (2012). Panorama das Pesquisas em Gestão de Projetos na Administração Pública. Recuperado de http://repositorio.uninove.br/xmlui/handle/123456789/93 